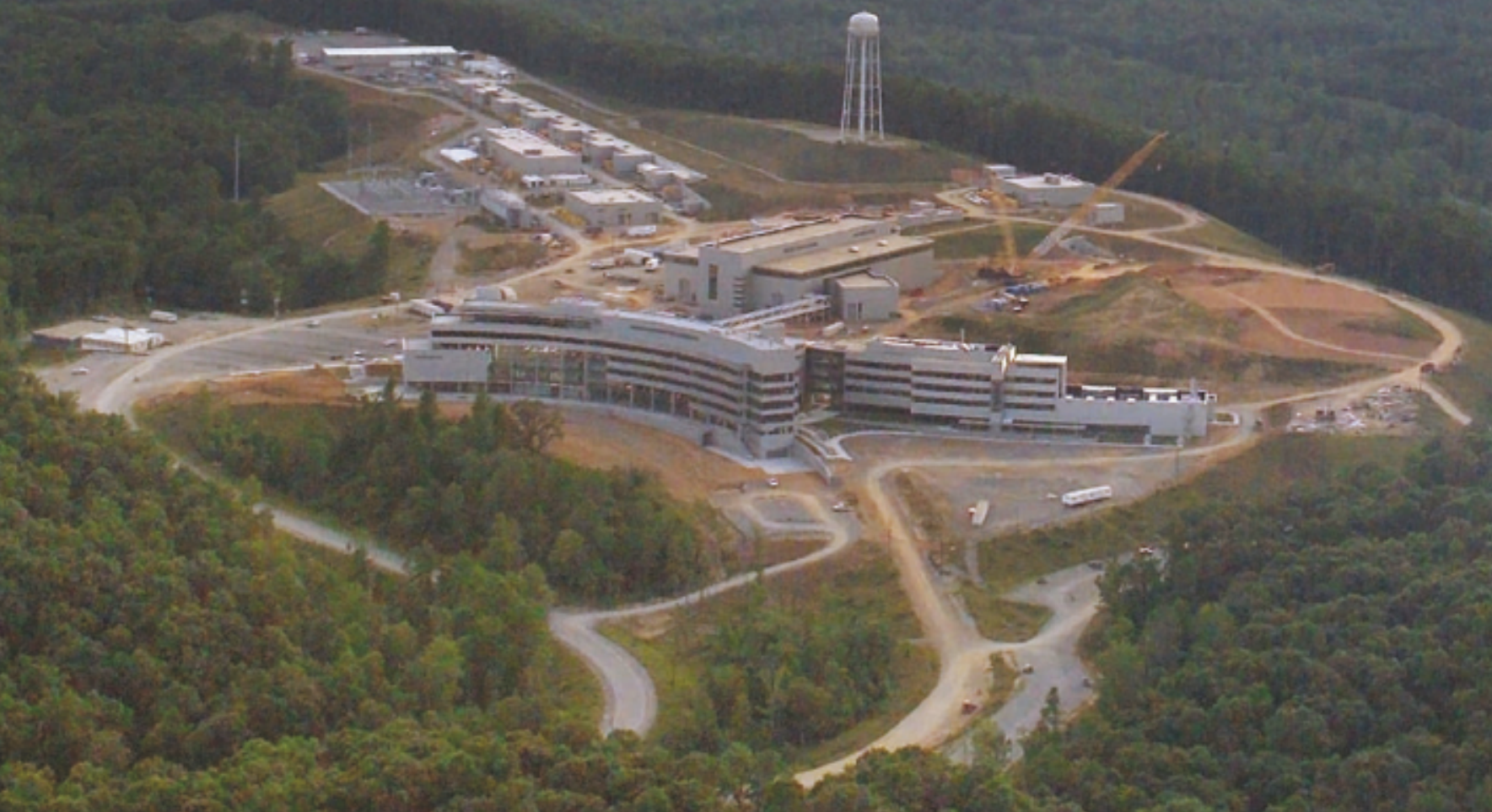

\title{
Back on track?
}

\section{Next June, a \$1.4-billion neutron-scattering facility will come online in the United States. Karen Fox finds out whether this machine really can breathe fresh life into the ageing Tennessee lab that is its home.}

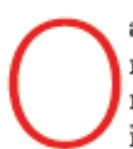

ak Ridge National Laboratory is more than 60 years old and, until recently, it looked that way. Despite its track record in nuclear research, the host of wildlife that wanders on campus, and the pretty sunsets over the rolling hills of eastern Tennessee, it looked unlikely to entice the energetic people who are the lifeblood of any great laboratory.

Salvation may be at hand. The Spallation Neutron Source (SNS), the largest scientific facility to be built in the United States for a decade, will become operational at Oak Ridge by next June. The \$1.4-billion machine will generate neutron beams by firing high-energy protons at liquid mercury. Hundreds of visiting researchers are expected to descend on the laboratory and use these beams to probe the structures of molecules and crystals.

"What this brings to the table is the opportunity to do an entirely new class of experi- ment," says Jack Rush, who retired earlier this year as director of neutron scattering at the National Institute of Standards and Technology (NIST) in Gaithersburg, Maryland.

Researchers around the world will be keen to assess the popularity and capabilities of the new facility. Once there would have been no question about the usefulness of such a resource. But in the two decades since the US Department of Energy (DOE) first planned a neutron facility at Oak Ridge, the options available for mapping molecular and crystalline structures have widened. Facilities that use X-rays to probe these structures, such as the Advanced Photon Source at Argonne National Laboratory in Illinois, have become vastly more powerful. Meanwhile, the number of researchers who work with neutrons has dedined as several ageing neutron-source facilities have closed.

Despite this, Japan is building a research facility similar to the SNS at Tokai, which will be ready in 2007. European plans for an even more advanced spallation source hit political setbacks a couple of years ago; their proponents are keen to revive them as a way of preserving the continent's long-standing lead in neutron science.

\section{Building excitement}

At Oak Ridge, the new neutron source is generating a palpable buzz. The facility managers are aware that many potential users of the technique have learned to live without it. So to bring them to a site far from the universities where they work will require exceptional management and technical support.

"You can have a philosophy of if you build it, they will come," says Paul Butler, team leader for NIST's small-angle neutron-scattering instrument. "But in my experience that doesn't work. You have to do more." Butler is 
on the SNS users group committee, formed when construction began in 1999, to make sure the neutron source goes that extra mile to meet scientists' needs.

Oak Ridge managers know they face a challenge. They anticipate that just a few hundred researchers will use the facility during its first two years of operation, while its neutron output slowly ramps up to its full potential. But they expect this to build up to 2,000 users a year by 2015 , as researchers currently accustomed to using advanced X-ray sources begin to be converted to the subtler and sometimes complementary charms of neutrons.

Supporters of the neutron source say that it does things that other mapping tools can't do. $\mathrm{X}$-rays bounce off electrons, and so scatter much more spectacularly from heavier elements that have many electrons than from lighter ones, such as hydrogen, which has only one. It has been estimated that, as a result, the placement of about half of the hydrogen atoms in published protein structures derived from $\mathrm{X}$-ray studies are not known. Neutrons interact directly with nuclei, making lighter atoms easy to identify.

\section{Structured approach}

Dean Myles, head of structural biology at Oak Ridge, points out that another advantage of dealing with nuclei, rather than electrons, is the ability to distinguish between different isotopes of the same element. This means that researchers can, for example, use deuterium a heavy isotope of hydrogen - as a marker for the position of a particular atom in a molecule or structure. "I liken it to a black cat in a snow field," says Myles. Because neutron sources can map structures over time, a molecule labelled with deuterium could, for instance, be watched as it wanders across the surface of a sample that mimics a cell membrane. Oak Ridge is keen to teach its users the chemical tricks necessary for such work, and the lab is also growing bacteria in deuterium-rich media so that they produce deuterated proteins.

Neutrons can also probe magnetic moments in solids and phenomena such as high-temperature superconductivity. Theories explaining superconductivity can be tested by mapping the position and movement of oscillations of the magnetic moment at a range of different atomic energy levels, Rush says. And the SNS should be able to collect these data some ten times more quickly than existing neutron facilities, owing to its high neutron flux.

This high flux level - up to $10^{17}$ neutrons per square centimetre per second - will also allow users of the facility to extract useful information from smaller samples. This, says Rush, is a valuable capacity for people studying things in short supply, such as proteins or newly developed polymers.

The facility also incorporates specialized equipment to cater for different research needs. One instrument will place samples under extremely high pressure, helping

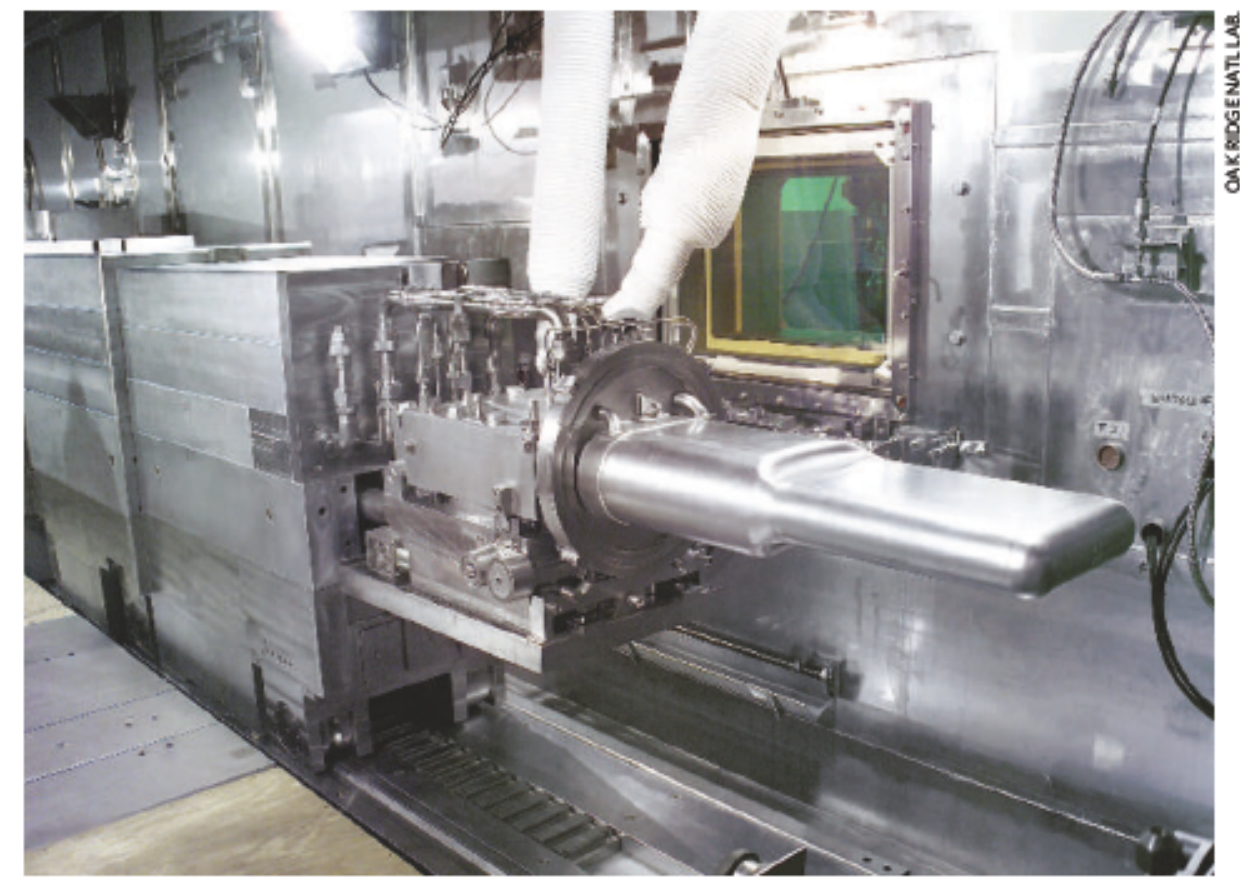

On target: mercury held inside this vessel will be hit by high-energy protons to generate a beam of neutrons.

planetary scientists who want to model the hydrogen-rich interior of Jupiter. Until now, it has been a struggle to reach pressures above 25 kilobars simply because of a lack of beam intensity at neutron sources, says Richard Nelmes, who specializes in high-pressure neutron science at ISIS, the British neutron facility near Oxford, which is currently the most powerful spallation source in the world.

For Oak Ridge - the largest of the DOE's civilian laboratories - the new facility provides a badly needed opportunity to regain scientific momentum. "It's a little bit of an engine you get rolling, says Jeff Wadsworth, Oak Ridge's director. "It generates an optimism that feeds on itself."

\section{Face lift}

Oak Ridge was built in 1943 to produce uranium and plutonium for the Manhattan Project, and a major new facility hasn't been added since the high-flux isotope reactor was built in 1966. ${ }^{\circ}$ There was first-class research and great people, but it looked like a decrepit 1950s lab," says Thomas Mason, who joined the SNS project at Oak Ridge in 1998, becoming the lab's

\section{"You put enough bright people}

together and interesting things happen." - PaulButler

associate director three years later. "People weren't working with state-of-the-art facilities."

Next year's opening is the culmination of a prolonged struggle to rectify that. Back in 1984, a National Academy of Sciences panel recommended the distribution of various scientific facilities to different DOElabs, with the largest one - a proposed advanced neutron- source reactor - allocated to Oak Ridge. But in 1995 Congress halted the \$2.9-billion project just before construction began.

The DOE decided to build a less expensive, accelerator-based neutron source instead: the SNS. Developed as a joint project between a number of the department's laboratories, including Los Alamos in New Mexico and Brookhaven in New York state, it was decided to locate the facility at Oak Ridge, in the home state of then-vice-president Al Gore.

After construction began, Oak Ridge's management contract was taken over by the University of Tennessee and Battelle, a contract research organization based in Ohio. The new management team has been working hard to secure extra investment for the lab: for instance, it has borrowed $\$ 115$ million from private banks to build associated infrastructure, including a new centre for computational sciences. On the back of that, Oak Ridge has won leadership of a large DOE supercomputing initiative.

${ }^{\alpha}$ There is a substantial amount of risk that goes along with the debt," says Wadsworth. "But we believed it would help to attract more contracts and to grow our business, and so far we've been successful.

Ultimately, Oak Ridge will measure its success by its ability to attract world-quality researchers - both as visitors and as staff. "You put enough bright people together and interesting things happen," says Butler. "There are all these buildings going up on the hill, and then you put in these people and resources, and add 1,500 users with all their new ideas." In these gentle southern hills, he predicts, "it's going to be a melting pot of ideas, bubbling away".

Karen Fox is a science writer based in

Washington DC. 